\title{
Prioridad teológico-pastoral de la pneumatología hoy
}

\section{Víctor Codina, S.J., profesor emérito de la Universidad Católica Boliviana de Cochabamba}

Los profundos cambios que experimentamos en el mundo de hoy a nivel social, económico, técnico, político, cultural y climático, repercuten necesariamente en el ámbito religioso y espiritual de la humanidad. Ya es un tópico hablar de crisis, de cambio de época y de cambio de paradigma, de una nueva era axial, de un terremoto seguido de un fuerte tsunami que todo lo sacude e invade. En este contexto globalizado, ¿cómo resituar la fe y la vida de los cristianos, de las Iglesias y de su misión evangelizadora? ¿Qué elementos de la identidad cristiana son irrenunciables y qué nuevos desafíos interpelan nuestra fe y nuestra praxis cristiana? ¿Cómo ser cristianos y cristianas en el siglo XXI? ¿Qué nuevos acentos e impulsos hemos de asumir en nuestra vida y misión cristiana de hoy?

\section{Cristocentrismo de la fe eclesial}

Empecemos reafirmando que Jesucristo constituye la identidad básica de la fe cristiana, de la Iglesia, de la evangelización y de la misión, ya que la esencia del cristianismo no consiste en una doctrina ni en una ética, ni en una filosofía religiosa que existan independientemente de Jesús de Nazaret, de su vida y de su misterio pascual.

Lo cristiano es su misma persona y él es el que determina el ser, el obrar y la doctrina del cristianismo. Fuera de él no hay salvación (Hch 4, 12), él es camino, la verdad y la vida (Jn 14, 6); Jesucristo es el centro del kerigma, de la liturgia y de la diaconía de la Iglesia; los primeros concilios fueron cristológicos para defender la divinidad del Hijo y la verdad de su encarnación en Jesús de Nazaret.

La cristología se ha desarrollado y renovado ampliamente en la segunda mitad del siglo XX, profundizando sus raíces bíblicas, integrando el Cristo de la fe con el Jesús histórico, redescubriendo la centralidad del Reino y de la 
opción por los pobres en su praxis mesiánica, resaltando la importancia de la resurrección en su misión salvífica, etc. Este capítulo es bien conocido y basta recordar los nombres de K. Rahner, E. Schillebeeckx, F. X. Durrwell, J. Moingt, J. M. Castillo, J. I. González Faus, entre los teólogos europeos; y los de L. Boff, C. Palacio, J. Sobrino, J. L. Segundo, C. Bravo, I. Ellacuría, M. Hurtado, entre los latinoamericanos.

Tanto la encíclica Redemptoris missio de Juan Pablo II (1990) como la misma declaración Dominus Iesu (2000), cuestionable en muchos aspectos, con razón han insistido en la centralidad salvífica de Jesucristo frente a los intentos de relativizar el misterio de Cristo en la historia de la salvación, en aras del diálogo interreligioso en el que pareciera que la figura de Cristo dificulta el acercamiento entre las religiones y espiritualidades. Hay que afirmar claramente que una cosa es desoccidentalizar, deshelenizar o descolonizar el cristianismo y otra muy distinta el descristianizar el cristianismo o limitarse a una cristología light.

Indudablemente, esta fe cristológica se ha enmarcado siempre en un contexto trinitario: Jesús es el Hijo del Padre, la Palabra hecha carne (Jn 1, 14), y el que nos promete y confiere el Espíritu (Jn 14-16; Lc 24, 49; Hch 2). Todo esto es ampliamente conocido, es algo que damos por supuesto, algo irrenunciable y que nos sirve como piedra de toque para discernir cualquier corriente o movimiento espiritual: en confrontación con la vida, muerte y resurrección de Jesús, se disciernen todos los espíritus (1 Jn 4).

\section{Olvido del Espíritu}

Pero muchas veces el centralismo de Cristo, sobre todo en Occidente, ha llevado a cierto olvido del Espíritu, a un cristomonismo, en expresión del teólogo ortodoxo Nikos Nissiotis, en el cual el Espíritu siempre queda como un apéndice final. Este tema también ya ha sido ampliamente estudiado'.

Este olvido del Espíritu en la Iglesia latina, además de haber reducido prácticamente la teología trinitaria a la trilogía Dios-Cristo-Iglesia, ha tenido consecuencias muy negativas en la praxis cristiana: prevalencia de lo doctrinal, de lo moral y ritual sobre lo vivencial y experiencial; inflación de lo jurídico, lo institucional y lo estructural de la Iglesia sobre lo comunitario, lo carismático y místico; pérdida de lo simbólico y poético; inflación del magisterio eclesiástico con poco respeto al sensus fidelium del pueblo de Dios; centralismo universalista romano frente a la legítima autonomía y sinodalidad de las Iglesias locales; guerras religiosas, cruzadas, inquisición y antisemitismo; postura apologética y

1. Y. M. Congar, El Espíritu Santo, Barcelona, 1983, p. 188; M. C. Luccheti de Bingemer, "El amor escondido. Notas sobre la kénosis del Espíritu en Occidente", Concilium, n. . 342, septiembre 2011, pp. 63-76; V. Codina, Creo en el Espíritu Santo, Santander, 1994, pp. 42-50. 
proselitista en la misión, inmovilismo, arrogancia eclesial y cerrazón frente al mundo secular y a sus avances modernos; favorecimiento de un cristianismo puramente sociológico y cultural; divorcio entre teología y espiritualidad, con el consiguiente debilitamiento de la fe del pueblo; alejamiento de la Iglesia y de la fe por parte de grandes sectores de la sociedad (intelectuales, científicos, políticos, obreros, jóvenes y actualmente las mujeres). El costo eclesial de este olvido del Espíritu ha sido muy serio y merece una profunda reflexión.

Pero, por otra parte, este olvido del Espíritu espontáneamente suscita sucedáneos y provoca reacciones contrarias, muchas veces excesivas, con riesgo de pneumatomonismo, con una espiritualidad y una pastoral que deja en la sombra la encarnación del Hijo y el compromiso cristiano que de ahí se deriva.

\subsection{Mariología}

De los sucedáneos del Espíritu vamos a centrarnos en el principal, que es la Virgen María, y en la mariología ${ }^{2}$.

En América Latina la devoción del pueblo por María y la peregrinación a sus santuarios es un hecho que marca profundamente la fe. Muchas veces el pueblo cristiano atribuye a María las características del Espíritu: rostro materno y femenino de Dios, que visibiliza la misericordia y ternura compasiva de Dios, consoladora, abogada, defensora de los fieles ante el juez Cristo y ante el Padre. María ejerce su maternidad con nosotros, nos da la vida de la gracia, nos muestra y revela a Jesús, es vida, dulzura y esperanza nuestra, nos lleva a Jesús, como lo expresa la célebre formulación "a Jesús por María". Incluso un conocido teólogo latinoamericano, al ver la devoción del pueblo por María se ha preguntado si no podría hablarse de una especie de unión hipostática entre el Espíritu y María, a semejanza de la encarnación del Verbo en Jesús.

Ciertamente, esta devoción mariana puede desembocar, y a veces desemboca, en una hipertrofia mariológica, con un déficit de cristología y de pneumatología, en riesgo de caer en una mariolatría, como los cristianos de la Reforma nos critican continuamente. Detrás de estos excesos hay una falta de evangelización realmente trinitaria sobre Cristo, el Espíritu y el amor del Padre, persiste en el pueblo sencillo, también en el no tan sencillo, un sentimiento latente de miedo y terror ante el juicio final y la posibilidad de condenación: María es buena, la "buenita", frente a un Dios justo juez, exigente y duro... Muchas veces los primeros misioneros promovieron la devoción a María con una clara intención apologética

2. Dejamos de lado otros dos sucedáneos del Espíritu que, según algunos autores, también han sido reales, la eucaristía y el papa, que, en expresión de Mons. Mauricio Lefêbvre, junto con María constituyen "las tres realidades blancas que Dios nos ha dado". Sobre este punto y el de la mariología, se puede ver lo que afirma Congar en su libro clásico ya citado, El Espíritu Santo, pp. 188-194. 
antiprotestante. Evidentemente, todos estos excesos, que no niegan la buena fe del pueblo, deben ser corregidos a la luz de una evangelización plena de la Palabra y del lugar que ocupa la devoción por María dentro de la historia de la salvación.

Pero hay otro aspecto de esta devoción mariana que no podemos olvidar. Hay que recordar que, a diferencia de la persona de Jesús que es visible, encarnada en la geografía y en la historia, con hechos y palabras que se han recogido en la tradición de los Evangelios, la persona del Espíritu es invisible, silenciosa, anónima, kenótica y oscura, sin nombre propio, fluida, dinámica, verbo más que sustantivo, y se expresa bíblicamente a través de símbolos cósmicos como el aliento vital y el viento, el agua, el fuego, el perfume, la unción del aceite, el ave y la paloma que vuela...

Pues bien, la tradición patrística oriental ha visto en María un icono no solo de la encarnación y de la Iglesia, sino del Espíritu Santo, por la especial vinculación de María con el Espíritu en la encarnación y en toda su vida. Como escribe el teólogo ruso Paul Evdokimov, "la virginal Maternidad de la Theotókos (Madre de Dios) es considerada como una figura del Espíritu Santo"’. Es más, Juan Damasceno afirma que María, en cuanto Madre de Dios (Theotókos), contiene toda la historia de la economía divina en el mundo ${ }^{4}$.

No se trata, pues, simplemente de criticar la devoción popular por María, sino de explicitar las dimensiones cristológicas, pneumatológicas y trinitarias que se contienen en el icono de María, de modo que no se convierta en un sucedáneo del Espíritu, sino en una imagen simbólica y en un signo visible que revele la acción del Espíritu en la historia de la salvación y en toda la vida cristiana ${ }^{5}$.

\subsection{Pentecostalismo}

Otro fenómeno a tener en cuenta es el auge del pentecostalismo en todo el mundo, también en América Latina, crecimiento tan importante que algunos autores lo comparan con el surgimiento del movimiento de la Reforma del siglo XVI. En realidad, hay que hablar de pentecostalismos, pues bajo esta palabra se incluyen el pentecostalismo clásico de comienzos del siglo XX, los movimientos carismáticos que existen en las Iglesias históricas tanto católicas como evangélicas y el neopentecostalismo reciente. El tema ha sido ampliamente estudiado por sociólogos y teólogos ${ }^{6}$, por lo que nos limitamos a constatar que

3. P. Evdokimov, Présence de l'Esprit Saint dans la tradition orthodoxe, París, 1969, p. 78.

4. De fide ortodoxa, III, 12, PG 94, 1029 C.

5. La exhortación apostólica de Pablo VI Marialis cultus, 1974, nn. 26-27, expresa bien la relación entre María y el Espíritu Santo.

6. Véanse el n. ${ }^{\circ} 119$ de Perspectiva Teológica, enero-abril 2011, dedicado a la Onda Pentecostal, y los artículos de Veli Matti Kärkkäinen, "El Espíritu derramado sobre toda carne'. Testimonios pentecostales del Espíritu Santo", Concilium, n. . 342, 
este acontecimiento, en medio de su gran pluralismo, es una crítica seria a una religiosidad cristiana excesivamente racional, fría, poco humana y poco sensible a los problemas y necesidades vitales del pueblo que en un mundo tan duro y cruel como el actual, busca experiencia espiritual, necesita conversión, salud y sanación espiritual y corporal, consuelo, inclusión social, alegría, fiesta, etc., y por esto se acoge al Espíritu de Pentecostés.

Es evidente que todos estos movimientos pentecostales necesitan ser discernidos a la luz del misterio de Jesús de Nazaret, pero esto no impide reconocer su importancia y el desafío pastoral y teológico que representan para las Iglesias. En el fondo, postulan un mayor reconocimiento teórico y práctico del Espíritu en la vida cristiana de hoy.

\subsection{Búsqueda de nuevas espiritualidades}

Finalmente, queremos decir una palabra sobre la New Age, nebulosa esotérica y confusa, ligada al paso de la constelación de Piscis a la de Acuario, que busca la fluidez, lo espontáneo, una espiritualidad holística, donde se integren el cuerpo y el cosmos, la armonía y paz interior, la reconciliación con el presente inmediato, con muchos elementos de las cosmovisiones orientales, muchas veces asumidas como religión a la carta, etcétera?

Es indudable que en medio de muchas ambigüedades y confusiones que necesitan un continuo discernimiento a la luz del Evangelio, la New Age es una crítica a una espiritualidad fría, desencarnada, racionalista y voluntarista, y, por otra parte, un anhelo de experiencias y realidades que desde la fe cristiana podemos identificar como una búsqueda anónima del Espíritu.

Bastan estos breves apuntes para mostrar que nuestra teología y praxis cristiana necesita una profunda reformulación y complementación desde la pneumatología. Hay que volver a recuperar el Espíritu.

\section{Necesidad de una complementación pneumatológica}

El Concilio Vaticano II (1962-1965) impulsó una renovación pneumatológica en la Iglesia, respondiendo a los deseos y oraciones de Juan XXIII que pedía que el Concilio fuese un verdadero Pentecostés para la Iglesia. Las críticas de los observadores ortodoxos, protestantes y anglicanos que reprochaban la falta de pneumatología de los textos que se discutían, fueron ampliamente escuchadas.

septiembre 2011, pp. 87-98; y de Leonildo Silveira Campos, "Pneumatologías en conflicto. Los 'pentecostales clásicos' y los 'neopentecostales' brasileños", Concilium, n. 342 , septiembre 2011, pp. 99-112.

7. Véase el Capítulo VII: La New Age, ¿mística o mistificación?, en J. Melloni, Hacia un tiempo de síntesis, Barcelona: Fragmenta Editorial, 2011, pp. 145-162. 
Congar enumera algunos de los avances positivos de la pneumatología conciliar: su pneumatología no es un pneumatocentrismo, sino una pneumatología claramente cristológica, el Espíritu es el Espíritu de Cristo, la Iglesia sirve al Espíritu de Cristo, es una comunidad unida por la unidad del Padre, del Hijo y del Espíritu, el Espíritu se halla presente en los sacramentos, sobre todo a través de la epíclesis, se recuperan los carismas en la Iglesia, el Espíritu actúa en la historia (GS), etcétera ${ }^{8}$.

Pero a pesar de estos avances positivos del Vaticano II, Pablo VI no dudó en afirmar que "a la cristología y especialmente a la eclesiología del Concilio, debe suceder un estudio nuevo y un culto nuevo sobre el Espíritu Santo justamente como complemento que no debe faltar a la enseñanza del Concilio"9.

Juan Pablo II también aportó a la pneumatología con su encíclica Dominum et vivificantem $(1986)^{10}$. Sin embargo, todavía hoy surgen voces pidiendo una revolución pneumatológica: "Una vez que la revolución cristológica se ha llevado a cabo (parcialmente, al menos), es el momento de que renazca (o mejor, simplemente nazca, porque nunca estuvo viva) una revolución pneumatológica. Esta podría ser la tarea para la teología del futuro"11.

Por su parte, el teólogo de Perú, Simón Pedro Arnold, afirma que hay que pasar de la cristología del Jesús histórico y de Gaudium et spes (GS 22; 32) a una cristología trinitaria y a la pneumatología, a la experiencia espiritual y la presencia del Espíritu en la historia, en consonancia con la teología oriental, los Santos Padres, los movimientos carismáticos, las religiones originarias ${ }^{12}$.

Me parece que la exigencia actual y lo más novedoso sería elaborar una especie de pneumatología fundamental que no se limitase a reconocer la presencia del Espíritu en la Iglesia y en el mundo después de Pascua-Pentecostés, como don del Resucitado, sino que profundizase también en la clave pneumática como condición necesaria de acceso a Cristo, como mediación que prepara los caminos del Señor en la creación, en la historia, en las personas y en la misma Iglesia. Es decir, una perspectiva pneumatológica que se halla ciertamente en Lucas y en Hechos, pero también en el Evangelio de Juan, como luego veremos. Esta primacía de la pneumatología se confirmaría con estas afirmaciones de Pedro Trigo: "Lo que al hablar de la Trinidad en sí va en último lugar, es decir, el

8. Y. M. Congar, El Espíritu Santo, op. cit., pp. 195-201.

9. Audiencia general del 6 de junio de 1973, citada en Y. M. Congar, op. cit., p. 201, n.o 17.

10. Véase un comentario actualizado de esta encíclica en P. D. Murray, "Dominum et vivificantem leída en el presente", Concilium, n. 342, 2011, pp. 163-168.

11. J. I. González Faus, "La Iglesia católica-romana no es la verdadera Iglesia de Cristo", Revista Latinoamericana de Teología, n. ${ }^{\circ}$ 83, mayo-agosto de 2011, p. 264.

12. S. P. Arnold, Ensayos andinos, Puno-Cochabamba, 2009, pp. 97-114. 
Espíritu, al hablar de nuestra relación a ella, él ocupa el primero"13 . "También por este motivo, la actualidad del Espíritu debe tener primacía"14.

Se trata, pues, de dar una prioridad teológico-pastoral a la pneumatología en la Iglesia de hoy, lo cual seguramente contrasta con una visión de la evangelización prioritariamente kerigmática, de anuncio de la Palabra, de formación bíblica y catequética... Pero ¿no vivimos una inflación de doctrinas, palabras, magisterio, catecismo, clases de religión, cursos de formación, homilías, transmisión de conceptos y tradiciones... frente a un déficit de experiencia espiritual, de interioridad, de iniciación, de silencio contemplativo y de mistagogía?

Para que nuestra propuesta no parezca extraña, habría que recuperar la tradición bíblica, patrística y litúrgica de la Iglesia.

\section{Aproximación bíblica}

No pretendemos aquí presentar una fundamentación bíblica de la pneumatología, sino solamente dar algunas pistas que ayuden a recordar que el Espíritu prepara los caminos del Señor.

El primer relato de la creación nos dice que "la tierra era woho -wa-bohu (caos, confusión) - , y las tinieblas cubrían el abismo, mientras la ruaj elohim aleteaba sobre las aguas" (Gn 1,2). La interpretación cristiana tradicional reconoce en la ruaj elohim una referencia al Espíritu Santo, una presencia anterior a la Palabra creadora que se refiere a Cristo $(\mathrm{Gn} \mathrm{1,3).} \mathrm{La} \mathrm{exégesis} \mathrm{histórico-crítica}$ se opone a esta interpretación que en Gn 1, 2 se trata de una descripción del caos típica del Oriente, en la que el Espíritu está fuera de lugar y que habría que traducir como la presencia de la tormenta de Dios, en el sentido de fuerte viento. Comentarios más recientes procuran mediar entre la perspectiva dogmática y la histórico-crítica, prestando más atención al tejido del texto y viendo en Gn 1,2 una mención al aliento de Dios: la Palabra de Dios que se expresará en forma creadora está presente desde el comienzo en el aliento de Dios. Y las tres traducciones asumen significados convergentes de la palabra hebrea ruaj que puede significar viento (Gn 2, 7; Qoh 1, 14.17), aliento $(1 \operatorname{Re} 19,12)$ y espíritus de diversa índole, que se mueve con la vibración del aleteo de un ave (Dt 32, 11), ave que anticipa las alas divinas que protegen al pueblo (Sal 91, 4) y que puede haberse desarrollado luego en la imagen del Espíritu como paloma (Mc 1, 10; Mt 3, 16; Lc 3, 22) $)^{15}$.

13. P. Trigo, "El método en teología", ITER, XXX años de Itinerancia, Caracas, 2010, p. 170.

14. Ibid., p. 203.

15. M. T. Wacker, "El Espíritu de Dios en el ámbito público de las comunidades cristianas. Inspiraciones tomadas de la Biblia hebrea", Concilium, n. ${ }^{\circ} 342,2011$, pp. 35-46. 
Lo que queda claro es la presencia amorosa del aliento vital, principio divino que capacita un universo emergente para ser y evolucionar y que la tradición cristiana interpretará como el Espíritu creador, inseparablemente unido a la Palabra ${ }^{16}$.

Este Espíritu es el que moverá con fuerza a las figuras que conducen a Israel, jueces, reyes y sobre todo profetas, que anuncian que el futuro rey mesiánico estará lleno del Espíritu (Is 11). Este Espíritu es el que suscitará el nacimiento de Juan Bautista (Lc 1, 15), que preparará los caminos del Señor. Este Espíritu es el que desciende sobre María de Nazaret (Lc 1,34), para hacer de ella la madre de Jesús. Este Espíritu desciende sobre Jesús en el bautismo (Mc 1, 10; Mt 3, 13; Lc 3, 21; Jn 1,32) y guía toda la vida de Jesús, como Lucas resalta continuamente (Lc 4, 1; 4, 14). También en el Evangelio de Juan aparece que el Espíritu es el que lleva a la verdad plena (Jn 16,13-15), el que enseñará a los discípulos todas las cosas haciéndoles recordar lo que Jesús les había dicho (Jn 14, 26), el que dará testimonio de Jesús (Jn 15, 26). Este Espíritu que Jesús posee y da sin medida (Jn 3,34) es el don del Jesús crucificado-exaltado en la cruz (Jn 19, 30), que luego comunicará a los discípulos en la Pascua (Jn 20, 19-23) ${ }^{17}$.

Este Espíritu es el que resucitará a Jesús de entre los muertos $(\mathrm{Rm} 8,11)$ y el que proseguirá la obra de Jesús desde Pentecostés (Hch 2). Los Hechos de los Apóstoles nos narran cómo el Espíritu anima la evangelización apostólica y cómo se derrama incluso a los gentiles en un Pentecostés semejante al de la primera comunidad (Hch 10). Pablo resumirá gráficamente esta relación estrecha entre el Espíritu y Jesús al afirmar que nadie puede decir: ¡Maldito sea Jesús! si está movido por el Espíritu, y nadie puede decir: ¡Jesús es el Señor! si no es movido por el Espíritu (1 Cor 12,3).

A todo lo anterior quisiéramos insinuar que hay que tener también en cuenta la importancia del secreto mesiánico en los Evangelios, sobre todo en Marcos, para evitar que el mesianismo de Jesús fuese mal comprendido antes de la Pascua (Mc 1, 25. 34.44; 3, 12; 5, 43; 7, 36; 8, 26.30; 9, 9). ¿No deberíamos hoy practicar también cierto secreto mesiánico en algunas circunstancias?

Indudablemente, esta línea teológica en la que el Espíritu antecede y prepara los caminos del Señor, que como hemos visto se halla también en Juan, no puede desconocer ni mucho menos estar en contradicción con el hecho de que la teología joánea liga estrechamente el Espíritu al misterio pascual de Jesús (Jn 7, 39; 19, 30; 20,22), pero una visión que redujese el Espíritu a después de la Resurrección de Jesús no daría cuenta cabal del misterio del Espíritu en la creación y en la historia. En palabras del teólogo y pneumatólogo Denis Edwards:

16. D. Edwards, Aliento vital. Una teología del Espíritu creador, Estella, 2008, pp. 67 y s.

17. J. O. Tuñí, El Evangelio es Jesús, Estella, 2010; y El do de la veritat (Jn 1, 17), Barcelona, 2011, pp. 132-137. 
"No deberíamos pensar que el Espíritu viene solo después de la Resurrección de Jesús. Él está activo en cada etapa de la historia de la salvación"18.

\section{Aproximación patrística}

Nos limitaremos también aquí a dar alguna referencia a cómo algunos padres de la Iglesia unen estrechamente cristología y pneumatología e insinúan una precedencia del Espíritu en orden a acceder a Jesucristo.

Es ya muy conocida la afirmación de Ireneo sobre las dos manos del Padre, el Hijo y el Espíritu, con las que Dios nos crea y acompaña siempre ${ }^{19}$. El mismo Ireneo, para explicar por qué el Hijo no se encarnó al comienzo de la creación, insinúa que Dios debía acostumbrarse a la humanidad y la humanidad tenía que ir acostumbrándose al modo de actuar divino, ya que Dios no es violento, no quiere imponer la comunión divina, sino que pedagógicamente espera el tiempo oportuno para cumplir su designio salvador de recapitularlo todo en Cristo ${ }^{20}$.

De San Basilio, el gran teólogo del Espíritu, tenemos esta conocida formulación:

La venida de Cristo, el Espíritu la precede.

La encarnación: de ella es inseparable el Espíritu.

Las acciones milagrosas, los carismas de curación: se dan por medio del Espíritu.

El diablo es rechazado, ante la presencia del Espíritu.

La redención de los pecados se da en la gracia del Espíritu. ${ }^{21}$

Y también en otro lugar Basilio afirma que el Espíritu antecede al hecho crístico: "El camino del conocimiento de Dios va desde el único Espíritu, pero por el único Hijo, hasta el único Padre. Y al revés, la bondad creativa, la santidad natural y la regia dignidad fluyen del Padre, por el Hijo hasta el Espíritu"22.

Y Paul Evdokimov, buen conocedor de la patrística oriental, concluye: "Se puede decir de una manera general, que la acción santificante del Espíritu precede todo acto donde lo espiritual toma cuerpo, se encarna, se convierte en cristofanía, manifestación de Cristo" ${ }^{23}$.

18. D. Edwards, Aliento de vida, Estella, 2008, p. 57.

19. Ireneo, Adv Haer 5,28,4; 4,7,4; 4,20,1;4,38,3; 5,1,3; 5,6,1; 28,4. Véase sobre este tema el estudio teológico de Luiz Eustaquio dos Santos Nogueira, $O$ Espírito e o Verbo. As duas mâos do Pai, Sao Paulo, 1995.

20. Ireneo, Adv Haer 5,1.1.

21. Basilio, De Spiritu Sancto 16.39.

22. Ibid., 18,47.

23. P. Evdokimov, Présence de l'Esprit Saint dans la tradition orthodoxe, op. cit., p. 87. 
La epíclesis litúrgica, tan característica del Oriente, también corrobora esta presencia y prioridad del Espíritu en la acción deificante de los sacramentos. El axioma lex orandi, lex credendi nos revela que la invocación al Espíritu en los sacramentos expresa esta fe y confianza en la acción del Espíritu de la Iglesia orante. El Espíritu es el que santifica, el que transforma los dones, el que realiza la comunión de los fieles con Cristo y entre sí. Nedio Pertile ha demostrado con profundidad que la teología pneumatológica de Paul Evdokimov se expresa bajo el signo de la epíclesis ${ }^{24}$, lo cual demuestra esta prioridad del Espíritu en toda la vida de la Iglesia. Esta línea de pensamiento teológico se puede extender al conjunto de padres y teólogos de la Iglesia oriental.

Pero todo el camino recorrido nos lleva a preguntarnos si esta precedencia del Espíritu al hecho cristológico tiene fundamento trinitario, pues ordinariamente la teología trinitaria occidental ha resaltado sobre todo que el Espíritu procede del Padre y del Hijo.

\section{6. Último fundamento trinitario}

Resumiendo muy brevemente el contexto de la problemática del Espíritu entre Oriente y Occidente, recordemos que el credo de Nicea profesa la fe en el Espíritu Santo y el de Constantinopla añade que el Espíritu es Señor y vivificante y procede del Padre. Más tarde, en los concilios III y IV de Toledo, para expresar claramente frente a los arrianos de España que el Hijo es Dios, se añade al credo niceno-constantinopolitano que el Espíritu procede del Padre y del Hijo (Filioque). Siglos después, por presiones, sobre todo políticas, Roma añade el Filioque al credo latino, hecho que Oriente no acepta y que en 1054 será una de la causas de la ruptura entre Oriente y Occidente ${ }^{25}$.

Oriente cree que el Filioque discrimina al Espíritu y provoca una dualidad en la Trinidad entre el Padre-Hijo, que actúan como un solo principio, y el Espíritu que procede de ambos.

Nos hallamos ciertamente ante dos teologías diversas de la Trinidad: la occidental, que Agustín desarrollará mostrando que el Espíritu es el lazo de comunión entre el Padre y el Hijo, y la oriental, que resalta la monarquía del Padre y no limita el Espíritu a ser el vínculo de la comunión intratrinitaria.

Tras siglos de infructuosas discusiones, en un clima más ecuménico, actualmente algunos teólogos del Oriente, como Evdokimov, llegan a admitir que el Filioque se puede aceptar si se completa con el Spirituque, es decir, con la

24. N. Pertile, Manifestado pelo Espírito Santo. Paul Evdokimov: Teología sob o signo da epíclese, Tesis doctoral defendida en Belo Horizonte, 2005.

25. Puede verse un mayor desarrollo histórico del Filioque en V. Codina, Los caminos del Oriente cristiano, Santander, 1997, pp. 22-24. 
afirmación de que el Hijo es generado por el Padre con la presencia amorosa del Espíritu $^{26}$. También de parte católica, F. X. Durrwell afirma que Dios es Padre y engendra al Hijo por el Espíritu y esto se manifiesta en la teología económica o ad extra en cuanto Jesús nace del Espíritu y es resucitado por el Espíritu ${ }^{27}$. El Padre engendra al Hijo amando y le resucita amando, y esta potencia divina es el amor, el Espíritu de Dios es amor. No hay que poner al Espíritu en tercer lugar, como una Persona estéril: el Espíritu ni es el comienzo, que corresponde al Padre, pero tampoco el final, está al comienzo y al final, pues el Padre engendra al Hijo en el Espíritu, es coeterno al Padre en su engendramiento y al Hijo en su filiación. No es estéril, es la misma fecundidad de Dios; por esto recibe de los fieles el mismo honor y gloria que el Padre y el $\mathrm{Hijo}^{28}$.

En palabras técnicas y un tanto escolásticas de K. Rahner, el Espíritu es causa eficiente del hecho crístico, pero Cristo es causa final de la acción del Espíritu ${ }^{29}$. En este sentido, toda cristología es pneumatológica, pues Jesús de Nazaret es el ungido por el Espíritu y es constituido Mesías y Cristo.

Indudablemente, esta concepción teológica del Espíritu puede extrañar a la mentalidad latina acostumbrada a situar al Espíritu al final de la Trinidad, pero, como afirma el teólogo ortodoxo B. Bobrinskoy, la Iglesia siempre ha oscilado entre el esquema Padre-Hijo-Espíritu y el esquema Padre-Espíritu-Hijo ${ }^{30}$.

Es necesario complementar dialécticamente la perspectiva joánea, agustiniana y latina del Filioque con la más lucana y oriental del Spirituque, pues hay pericoresis, inter-compenetración, circuncesión entre ambas. El Espíritu será siempre el Espíritu de Jesús, las dos manos del Padre son inseparables, filiación y procesión coexisten eternamente en igualdad y reciprocidad de comunión, la fuente última es el Padre, cuya esencia es engendrar infinitamente al Hijo en el Espíritu $^{31} \cdot$ ¡Estamos ante el Misterio!

\section{Actualidad pastoral}

Si esta reflexión pneumatológica es correcta, debe marcar e influir en los diversos campos de la pastoral, pues toda teología en última instancia se refiere a la praxis eclesial. Organizaremos la problemática a la luz de las tres dimensiones del Espíritu: la mística o interior, la profético-ética y la cósmica.

26. P. Evdokimov, Présence de l'Esprit Saint dans la tradition orthodoxe, op. cit., p. 71.

27. F. X. Durrwell, Nuestro Padre. Dios en su misterio, Salamanca, 1990, pp. 90-102.

28. F. X. Durrwell, Jésus Fils de Dieu dans l'Esprit Saint, París, 1997, pp. 97-99.

29. K. Rahner, Curso fundamental sobre la fe, Barcelona, 1979, pp. 369-371.

30. B. Borbrinskoy, Le Mystère de la Trinité, París, 1975, p. 78.

31. F. X. Durrwell, Jésus Fils de Dieu dans l'Esprit Saint, op. cit., p. 113, donde cita un texto del Maestro Eckhart: "La aspiración suprema de Dios es engendrar", Sermo 11, Impletum est tempus Elisabeth. 


\subsection{Dimensión mística}

Esta prioridad del Espíritu sobre la cristología significa que no se puede acceder a la fe cristiana y a la Iglesia sin una experiencia interior, llámese sapiencial, espiritual o mística. Esto significa que tanto la primera como la nueva evangelización no puede comenzar impartiendo ideas o normas, sino que ha de ser ante todo mistagógica, una iniciación a la experiencia espiritual, una experiencia fundante, un evento, un encuentro, sin lo cual no se puede comenzar a ser cristiano $^{32}$. La misión antes de ser un anuncio del kerigma cristológico y eclesial ha de ser experiencial y dialogal, iniciando a la experiencia y partiendo de la experiencia de los demás, algo así como Pablo hace en el Areópago de Atenas al partir de su adoración al Dios desconocido (Hch 17, 23). Es necesaria una apertura previa a la Trascendencia, al Absoluto, al Espíritu, antes del anuncio del kerigma pascual. Es preciso poseer una paciencia pedagógica e histórica, como la de Dios en la historia de la salvación, e incluso asumir un cierto silencio mesiánico, para preparar pneumáticamente los caminos del Señor, reconociendo su presencia, antes de dar nombre a esta experiencia mística y profética que brota del Espíritu de Jesús muerto y resucitado. El Espíritu ha llegado siempre antes que los misioneros evangelizadores cristianos. Esta actitud está muy lejos del proselitismo y de la prisa por ganar nuevos adeptos...

La misión evangelizadora se parece más a la tradición de la paternidad espiritual que a la del profesor, del catequista, del doctrinero, del maestro. Como afirma un teólogo espiritual católico de rito oriental: "Sin paternidad-maternidad espiritual la nueva evangelización no tendrá la penetración y profundidad necesarias para cumplir de veras su propia misión en una Europa que está profundamente descristianizada" 33 .

Esta prioridad de la experiencia espiritual hoy reviste una acuciante actualidad, como ya afirmó proféticamente K. Rahner en los años de postconcilio: se necesita una mistagogía o iniciación a la experiencia espiritual, de modo que el cristiano del futuro o será un "místico", es decir, una persona que ha "experimentado" algo, o no será cristiano ${ }^{34}$.

Hoy día no solo encontramos a cristianos que tienen un cierta creencia sin pertenencia eclesial ${ }^{35}$, sino también a muchos cristianos, tanto en los países del Norte como en América Latina, que tienen sentido de pertenencia eclesial, pero sin una auténtica creencia cristiana, es decir, han sido bautizados en la Iglesia de

32. Benedicto XVI, Dios es amor, n. 1 .

33. M. I. Rupnik, En el fuego de la zarza ardiente, Madrid, 1998, p. 102.

34. K. Rahner, "Espiritualidad Antigua y actual", Escritos de teología, VII, Madrid, 1967, p. 25.

35. G. Davie, Religion in Britain since 1945. Believing without belonging, Oxford, 1994. 
cristiandad, pero muchas veces no creen ni son discípulos ${ }^{36}$. ¿Por qué Aparecida tomó como lema el ser discípulos de Jesucristo en un continente en el que la mayoría han sido ya bautizados?

¿Por qué los dictadores de América Latina asesinaban en nombre de la civilización cristiana occidental? ¿Por qué América Latina, el continente con mayor número de cristianos, es el más injusto y desigual? ¿No será porque ha habido una evangelización doctrinal pero no experiencial, que ha llegado a la cabeza, pero no ha penetrado en el corazón?

Esta actitud mistagógica no solo puede ayudar al diálogo con el mundo secular, agnóstico o ateo, sino también con los que buscan una espiritualidad al margen de las instituciones religiosas, como la New Age y otros intentos un tanto gnósticos de una espiritualidad secular, laical, sin dioses ni creencias... Seguramente, a partir de sus búsquedas y experiencias espirituales es posible entablar un diálogo respetuoso y constructivo, enriquecedor para ambos, pues el Espíritu del Señor ha sido derramado sobre toda la humanidad.

Lo mismo vale para el diálogo interreligioso, tanto con las grandes religiones de la humanidad como con las religiones originarias, por ejemplo de América Latina. Las religiones son fruto del Espíritu (RH 6), la gracia de Cristo comunicada por el Espíritu permite llegar a la salvación a todos (RM 10), el Espíritu permite asociarse al misterio pascual en la forma solo de Dios conocida (GS 22), hay acción del Espíritu antes de Cristo, desde el principio (DV 33), el Espíritu está presente en las preguntas existenciales y religiosas de la humanidad (RM 28-29), hay mediaciones parciales de salvación que alcanzan únicamente su sentido por la mediación de Cristo (RM 5). El diálogo exige una postura de humilde purificación, de fecundación y de búsqueda de síntesis superiores, muy lejos del expansionismo imperialista o del aislacionismo tribal ${ }^{37}$.

Dicho de otro modo, la afirmación evangélica de que los cristianos somos sal de la tierra y luz del mundo (Mt 5, 13-16) implica una doble dimensión ${ }^{38}$. La sal significa dar sabor, ser testigos, ser presencia encarnada en la realidad, solidaridad con los gozos, esperanzas, tristezas y angustias del pueblo, sobre todo de los pobres (GS 1); mientras que la luz se refiere a la dimensión de anunciar

36. Como en la expresión "être sans croire" ( $c f r$. D. Hervieu-Léger, Le pélerin et le converti, París, 1999, p. 57), que se puede traducir como pertenencia sin creer, es decir, incrédulos postcristianos que quieren mantener símbolos cristianos porque pertenecen a la cultura occidental; $c f r$. L. González Carvajal, "Cristianos sin Iglesia", Concilium, n. ${ }^{\circ}$ 340, abril 2011, pp. 267-273.

37. J. Melloni, Hacia un tiempo de síntesis, op. cit., pp. 21-41.

38. J. Martín Velasco, "La sal y la luz. Dos dimensiones de la presencia de las comunidades cristianas en la sociedad", Sal Terrae, n. ${ }^{\circ}$ 1166, tomo 100, abril 2012, pp. 295-308. 
explícita y públicamente a todos la buena del Evangelio, el kerigma. Estas dos dimensiones, una más pneumática y otra más explícitamente cristológica, no se excluyen, son complementarias.

Tal vez estamos acostumbrados a creer que la urgencia misionera exige cuanto antes la proclamación del kerigma, pero una evangelización, antigua o nueva, que no prepare antes los caminos del Señor, que no parta de la realidad, que no escuche sus clamores y que no tenga paciencia histórica, puede convertirse en la semilla que cae en el camino o en una luz que deslumbra, pero que se deshace como los fuegos artificiales. No podemos olvidar que el Espíritu es el que prepara los caminos del Señor, nos hace comprender el mensaje de Jesús y abre los corazones de los fieles. ¿No es esta misma convicción teológico-pastoral la que subyace al método latinoamericano de ver-juzgar-actuar que ha optado por partir de la realidad, una realidad muchas veces dolorosa, pero que está siempre trabajada por el Espíritu de Jesús?

\subsection{Dimensión profético-ética}

El Espíritu no nos encierra en un misticismo interiorista y alejado de la realidad. El Espíritu que habló por los profetas, el que ungió a Jesús de Nazaret y le impulsó a evangelizar a los pobres y llevar la buena nueva a los que sufren, es el mismo impulso que nos lleva a nosotros a proseguir el camino de Jesús.

Pero esta dimensión profético-ética no es algo meramente voluntarista o moral, sino que es fruto de la unción del Espíritu que nos hace descubrir en los demás una presencia sagrada. El Espíritu que hizo que los profetas discernieran los signos de los tiempos y descubrieran en el clamor del pueblo la voz del Espíritu que clama por justicia y equidad, es el mismo que nos mueve hoy a nosotros a abrirnos a su clamor y a discernir los signos de los tiempos, pues creemos que el Espíritu es el que rige y mueve la historia y llena el universo (GS 11).

La Iglesia de América Latina que desde Medellín (1968) y Puebla (1979) optó por los pobres no lo hizo por motivos puramente sociológicos y humanitarios, sino movida interiormente por el Espíritu que le hacía descubrir en los rostros doloridos de estos hermanos excluidos el rostro del Señor crucificado (Puebla 31-39), y afirma en Aparecida (2007) que la opción por los pobres está implícita en nuestra fe cristológica y que todo lo que tenga que ver con Cristo tiene que ver con los pobres (Aparecida 393). Si no es posible reconocer a Jesús como salvador si no es por el Espíritu (1 Cor 12, 3), solo el Espíritu nos puede hacer descubrir en el rostro del pobre el rostro del Señor. De este modo, seguir a Jesús pobre implica optar por los pobres y este seguimiento, bajo la unción y la fuerza del Espíritu, se convierte en nosotros en fuente de vida plena, "humanización" 
para nuestra mentalidad moderna occidental, verdadera "divinización" para el Oriente cristiano ${ }^{39}$.

A nivel teológico, la teología de la liberación nace de una verdadera experiencia espiritual, de experimentar la presencia del Señor en el clamor de los pobres y la sacralidad de los hermanos y hermanas pobres. Sin esta experiencia espiritual previa, no se comprende esta teología que fácilmente puede ser tachada de sociológica, reduccionista o marxista. Muchas incomprensiones acerca de la teología de la liberación nacen en parte de que sus censores críticos no han tenido esta experiencia espiritual. El pobre en América Latina ha devenido un auténtico lugar teológico, y la teología de la liberación se ha convertido con el tiempo en una teología martirial. Y todo ello no se explica sin la presencia actuante del Espíritu: el dedo de Dios está aquí (Lc 11, 20).

Pero a partir de la década de los 90 hay un cambio de rasante cultural y teológica, se pasa de la segunda Ilustración, centrada en la injusticia y los pobres, a la llamada tercera Ilustración, abierta a la alteridad y diversidad ${ }^{40}$. El Espíritu es el Espíritu de la diversidad y alteridad pentecostal.

Los pobres tienen sexo, cultura, religión, edad, sabiduría, no son solamente unos pobres excluidos. Esto ha llevado a discernir al Espíritu en el clamor de los jóvenes, de las mujeres, de los indígenas y afroamericanos que son ciertamente una alteridad excluida, pero no son solo pobres, objeto de nuestra atención solidaria, sino sujetos de gran riqueza y potencialidad humana y espiritual. A través de su clamor, clama el Espíritu pidiendo respeto a su identidad y dignidad, igualdad de derechos, necesidad de ser escuchados y acogidos, de constituirse en agentes de una nueva sociedad y de una nueva Iglesia.

El tema ya ha sido ampliamente estudiado ${ }^{41}$ y estamos ante el surgimiento de una teología feminista, intercultural, juvenil, indígena, afroamericana, india... Detrás de todo ello está la fuerza vivificante de la ruaj que hay que acoger, escuchar, discernir antes de pretender evangelizarla, como Jesús escuchó a la mujer cananea y cambió de parecer $(\mathrm{Mc} 7,24-30)^{42}$.

39. J. Comblin, El Espíritu Santo y la liberación, Madrid, 1987; G. Gutiérrez, Beber en su propio pozo, Lima, 1983; J. Sobrino, "Espiritualidad y seguimiento de Jesús", en Mysterium liberationis, II, Madrid, 1990, pp. 449-476.

40. V. Codina, Capítulo 10: La Tercera Ilustración, en Una Iglesia nazarena, Santander: Editorial Sal Terrae, 2010, pp. 163-180.

41. V. Codina, "No extingáis el Espíritu” (1 Ts 5, 19). Una iniciación a la Pneumatología, Santander: Editorial Sal Terrae, 2008, pp. 178-216.

42. Véase el magnífico estudio de L. Cerviño sobre este pasaje en Otra misión es posible, Cochabamba, 2010. 
En resumen, no hay ética ni profecía sin una mística, sin una experiencia previa del Espíritu del Señor. Y al revés, toda verdadera mística lleva al compromiso ético, el Espíritu nos impulsa a seguir a Jesús y sus opciones.

\subsection{Dimensión cósmica}

Por una larga serie de motivos, el Occidente cristiano ha ido asumiendo una postura negativa sobre el cuerpo y el mundo, actitud que contrasta con las experiencias del mundo oriental, cristiano y no cristiano, y de las religiones originarias o aborígenes estrechamente ligadas a la tierra. Como reacción, se produce hoy un fuerte descubrimiento y revaloración del cuerpo y una gran preocupación por la ecología.

Esto nos lleva a redescubrir también el sentido del Espíritu creador que desde el big bang inicial hasta el final de la historia da vida y aliento a toda la creación, de la cual los seres humanos formamos parte junto con las galaxias, estrellas, rocas, pájaros, reptiles, cetáceos, bosques y flores.

Esta presencia del Espíritu creador en el hermano sol y la hermana luna del cántico franciscano, este Espíritu de Dios que "habita en las criaturas, en los elementos dando ser, en las plantas vegetando, en los animales sensando, en los hombres dando entender" de los Ejercicios ignacianos ${ }^{43}$, las bellas páginas de Teilhard de Chardin sobre el dinamismo de la materia hacia el punto omega... pueden servirnos de puntos de partida para replantear hoy la presencia del Espíritu en la creación, presencia que está atravesada trágicamente por la gravísima crisis ecológica que padecemos.

Elisabeth A. Johnson establece tres dimensiones de esta presencia inmanente del Espíritu en la realidad cósmica: una presencia creativa, el viento y aliento de la ruaj que da vida y renueva la faz de la tierra; una presencia inmanente cruciforme del Espíritu que en medio de situación de muerte biológica y de violencia está en dolores de parto ( $\mathrm{Rm} 8,22-23)$; y una presencia prometedora que avanza desde la génesis inicial hacia la novedad del futuro de Dios y nos lleva a la tierra nueva y a los cielos nuevos (Ap 21, 5) $)^{44}$.

Esta presencia e inhabitación del Espíritu en la materia cósmica y en nuestro mismo cuerpo nos ofrece una visión holística y sacramental de la realidad creada, que al decir de Tomás de Aquino participa del ser divino ${ }^{45}$, la tierra

43. Ignacio de Loyola, Ejercicios espirituales, n. ${ }^{\circ}$ 235. Que estas afirmaciones de Ignacio se refieren al Espíritu he intentado mostrarlo en V. Codina, Una presencia silenciosa. El Espíritu Santo en los ejercicios ignacianos, Cuadernos Eides n. . 62, Barcelona, 2011.

44. E. A. Johnson, "El espíritu creador y ética ecológica", Concilium, n. ${ }^{\circ}$ 342, 2011, pp. 23-34.

45. ST, I, q 8. 
es tierra sagrada. La creación es un icono del amor divino, sacramento de la presencia de Dios, del amor que mueve las estrellas.

Indudablemente, esta visión pneumatológica de toda la creación fundamenta de raíz una ética ecológica que mira a la creación como sacramento, no como objeto de consumo y depredación, que la estima como parte del proyecto de comunión del Dios trinitario que quiere que todos participemos de la tierra y la respetemos como Tierra Madre para todas la generaciones. De ahí nace también una postura profética contra todo abuso de la creación y el compromiso por salvaguardarla. El precepto "no matarás" incluye hoy también, por ejemplo, salvar a la selva tropical...

Es claro que esta dimensión ecológica y cósmica del Espíritu antecede a la proclamación del Evangelio de Jesús resucitado y puede ser compartida con personas de buena voluntad de todas las culturas y religiones, y extendida a todos los que buscan el respeto a la vida, a las personas y al resto de la creación.

\section{Conclusión: tiempo de adviento}

Evidentemente, esta defensa de la pneumatología y de la prioridad del Espíritu en la teología y la pastoral no quiere suscitar ningún movimiento de entusiasmo salvaje, ni de anarquía eclesial, ni actualizar el joaquinismo medieval, ni propiciar una espiritualidad gnóstica sin Iglesia, sin Cristo y sin Dios. Tampoco quiere desembocar en un apofatismo permanente, sino que se encamina a un anuncio explícito de Jesús, porque la vida que la ruaj genera en medio del caos del tohu$w a-b o h u$, alcanza su plenitud en Jesús de Nazaret muerto y resucitado y tiene en la Iglesia su sacramento visible. El Espíritu es el Espíritu del Señor Jesús, y en conformidad con su vida, su kénosis, su cruz y su resurrección, se deben confrontar y discernir todos los movimientos de los espíritus existentes. Las manos del Hijo y del Espíritu no se pueden confundir, pero tampoco separar.

Lo que hemos querido expresar es no solo la urgencia de recuperar la pneumatología, sino además la importancia de destacar que el Espíritu es quien desde la creación nos conduce a Cristo, prepara sus caminos y lleva adelante su misión. Y aunque desde la Pascua ya ha irrumpido la presencia de la escatología, tanto la Iglesia como la humanidad todavía están en camino hacia la plenitud del Reino, hacia la parusía y hacia los nuevos cielos y la nueva tierra, y en este caminar es el Espíritu el que nos recuerda el Evangelio de Jesús y nos hace llegar a la verdad plena, como nos recuerda el Evangelio de Juan. En este caminar, el Espíritu continúa presente y actuante, como lo estuvo desde el comienzo de la creación, a través de Israel, de la Iglesia y de la humanidad, a través de los movimientos, culturas y religiones. Bajo la fuerza de este Espíritu hemos de iniciar ante todo una pastoral mistagógica, profética y cósmica, que seguramente muchas veces deberá preceder al anuncio del kerigma. 
Estamos todavía en tiempo de Adviento, un Adviento que no es simplemente un memorial litúrgico de la primera venida de Jesús, sino uno histórico y escatológico que con toda la humanidad espera la venida definitiva del Señor. Es tiempo de espera y de esperanza, de diálogo y de anuncio, de paciencia y vigilancia, tiempo de silencio apofático y de plegaria anónima de toda la humanidad, de epíclesis cósmica que se expresa en las palabras de la esposa que junto al Espíritu le piden al Señor que venga (Ap 22, 17). Hoy, como ayer, en el Adviento de la historia, el Espíritu prepara los caminos del Señor: "Ven, Señor Jesús" (Ap 22, 20). 